Geraldine Scanlon $\mathrm{PhD}$ (corresponding author)

Dublin City University, Republic of Ireland

Address Institute of Education, School of Human Development, Dublin 9

Phone +35318842036

E-mail_geraldine.scanlon@dcu.ie

ORCID 0000-0003-4331-5582

Annelies Kamp PhD

Dublin City University, Republic of Ireland

Postal Private Bag 4800, Christchurch 8140, New Zealand

Phone +6433693632

E-mail_annelies.kamp@ canterbury.ac.nz

ORCID 0000-0002-9442-0908

Andy Cochrane PhD

Maynooth University, Republic of Ireland

Address Department of Psychology, Co. Kildare.

Phone +35314747138

E-mail andy.cochrane@nuim.ie

ORCID 0000-0003-4867-2677 


\title{
Transition(s) to work: the experiences of people with disabilities in Ireland.
}

\begin{abstract}
Whilst disability policy in Ireland has advanced in recent years, the underrepresentation of people with a disability in the workforce continues to be a social and economic challenge. Education and training have been identified as critical factors enabling a move into paid employment yet little is known, in an Irish context, as to the experiences of people living with disabilities as they transition into work. This qualitative study explores the views and perceptions of a diverse group of people with disabilities who are attempting, or have already made, a transition from education or training to work in the context of fluid $21^{\text {st }}$ century labour markets. Key issues identified in the research include self-perceptions of work-readiness, concerns related to disability disclosure and the need for more flexible approaches to work-place accommodations.
\end{abstract}

Keywords: transition; disability; employment; education; training

Funding: This work was supported by the National Disability Authority in Ireland. 


\section{Points of Interest}

- This study explored the experiences of people with disabilities making transitions from education and training to employment.

- Providing meaningful employment for people with disabilites after the recession

- Transition planning was often absent to assist people with disabilites make a success move into further education and the workplace

- The majority of the respondents in the study reported here want to work, but identified persistent barriers in moving into employment. 


\section{Introduction}

In Ireland in the $19^{\text {th }}$ Century, the advantages of work in the form of paid employment were lauded by early capitalists and the clergy. Work increased productivity at the expense of leisure; while 'free' creative labour was the source of both material and cultural sustenance, the evolution of what Marx conceptualised as 'alienated labour' under capitalism led to the notion of the 'tyranny' of work (Rienhart 2006). In this evolution, the proletariat were argued to have been corrupted by "the dogma of work" (Lafargue, 1883, p.13). Work was portrayed as enabling social and personal wealth yet this was to the detriment of personal well-being. In the $21^{\text {st }}$ Century Ireland, paid employment continues to be taken up as a key marker of adulthood and citizenship, as 
well as acting as the primary mechanism for economic wellbeing. Indeed, the right to work is enshrined in Article 27 (1) of the Convention of the Rights of People with Disabilities ratified by Ireland in 2018 .

States Parties recognize the right of persons with disabilities to work, on an equal basis with others; this includes the right to the opportunity to gain a living by work freely chosen or accepted in a labour market and work environment that is open, inclusive and accessible to persons with disabilities.

This prioritisation of work, and the 'right' to engage in it, persists despite recent shifts in the context of work in Ireland, and beyond. First, the labour market in Ireland changed dramatically in the wake of the 2008 Global Financial Crisis. The resulting Irish recession severely compromised opportunities for all people seeking work. Second, such work as there is, is increasingly 'casualised' and has resulted in a new form of the proletariat - the 'precariat' (Standing 2011). In this context, many workers will experience new career forms and an on-going requirement to engage with learning so as to meet employer needs for flexibility in highly competitive, globalised markets. New career forms offer both opportunities, and risks, for workers. However, people with disabilities are understood to have additional complexities to manage both in beginning work and in remaining resilient in the face of likely employment changes. The complexity of this is borne out in statistics confirming the under-representation in employment of people with disabilities (World Health Organisation 2013; CSO 2016)

The purpose of this paper is to present research that captured the perspectives of people with disabilities who were in transition from education and training to employment in the Republic of Ireland as it recovered from recession in the wake of the 2008 Global Financial Crisis The paper provides a focused review of the Irish 
employment and education context and presents relevant disability policy to contextualize the complexities of the transition process, as perceived and experienced by people with disabilities in Ireland in the context of changing labour market opportunities.

\section{The Irish Context}

The broader socio-economic context at the time of this research is pertinent to its topic. As the Global Financial Crisis of 2008-2009 swept beyond the United States, the Irish economy collapsed from the economic highs of the preceding Celtic Tiger years (see Lewis 2011 for a detailed overview). The collapse had consequences for all citizens but, particularly, for people in transition to first-time employment and those without established stores of work experience who found themselves competing for limited work opportunities with experienced workers who had been made redundant. While economic recovery is now underway, radically decreased rates of unemployment do not guarantee that 'decent' jobs will suddenly become available for all those who want them and particularly not for people with disabilites.

Educational attainment is just one factor in explaining employment outcomes achieved by people with disabilities. Experiencing difficulties in securing work and assumptions regarding the job-readiness, or otherwise, of an individual on the basis of a disability can reinforce negative messages of low expectations and poor aspirations (Sayce 2011). Globally, employers' attitudes towards the recruitment and retention of employees with disabilities have been studied extensively, with mixed and inconsistent findings (e.g. Millbank Foundation for Vocational Rehabilitation 2003; Waterhouse et al. 2010; Needels and Schmitz 2006). There is a tendency, however, to consider people with disabilities as a homogenous group rather than as individuals with specific skills, abilities and talents. Consequentially, being labelled as someone with 'a disability' can 
negatively influence prospective employers' perceptions about ability, safety issues and work performance (Shier, Graham and Jones 2009). Employers who are not aware of the issues surrounding disability may not consider employing someone with a disability, particularly if there are suitable candidates who have not disclosed any disability (Piggott and Houghton 2007).

The most recent census in Ireland indicated that $13.5 \%$ of the Irish population $(643,131)$ stated they had a disability; $30.2 \%$ of whom were participating in the labour market, compared to $61.4 \%$ of the overall population (CSO, 2016). Consistent with international data, the education level of people with disabilities in Ireland is substantially lower than those of their non-disabled peers. The CSO (2016) figures indicate that within the age range of $15-50,13.7 \%$ of individuals with one or more disabilities did not continue on their education after primary level, compared to only $4.2 \%$ of the general population. Furthermore, third level education was achieved for only $37 \%$ for those with disabilities compared to $53.4 \%$ of the general population.

Over recent years, disability policy in Ireland has shifted from a medical model which focused on the culture of dependency and was generally provided by charitable organisations, towards a social model and the provision of individualised supports to remove barriers to enable full participation in society for people with disabilites (Watson et al. 2015). This shift foregrounds a challenge to the valorisation of 'work' and 'productive bodies', allowing space for consideration of individual interests and aspirations. The dependency culture which was traditionally embedded in segregated and institutionalized settings for people with disabilities is currently being dismantled in tandem with changes in international practices, in an effort to promote selfdetermination and independence (Fleming, Mc Gilloway and Barry, 2016). 
Within a social model, the barriers which people with disabilities encounter in seeking a fulfilled life are constructed by the individualized structures of economies and societies and fail to reflect the individual's needs and desires which are often achieved in a context of community and interdependence (Oliver, 2013). Building on this concept, the principles of the Independent Living Movement endorses the notion that everybody has the right to a certain standard of living, to be treated with respect (White et al. 2010), and to have choice in what services they require (DeJong 1979).

To date, disability policy in relation to work in Ireland is supported by a legislative framework which includes the Employment Equality Acts (1998; 2004). These Acts prohibit discrimination on certain grounds including disability; additionally, the Acts require employers to take reasonable steps to accommodate the needs of existing and prospective workers with disabilities. Such accommodations include modification to the tasks or structure of the work or workplace, thereby allowing the worker with a disability to experience equal opportunities in the employment. However, under EU legislation employers are not obliged to provide special treatment or facilities if the cost of doing so is deemed excessive or disproportionate.

The Disability Act of 2005 places significant obligations on public bodies to ensure that buildings and services are fully accessible, and requires positive action to employ people with disabilities (Department of Justice, Equality and Law Reform, 2006). The latter provision gave legal status to a $3 \%$ target for employment of people with disabilities in the public sector (not applicable to the Defence forces, An Garda Síochána and the Prison services). The 2013 census of staff in the public service indicated that whilst the overall the target of $3 \%$ had been reached, 47 out of 239 state bodies, included the Equality Authority, reported having no worker with a disability on their staff ( The Irish Examiner, 2015). More recently, the Comprehensive Employment 
Strategy (CES) for People with Disabilities (Government of Ireland, 2015) sets out an ambitious 10-year plan designed to ensure 'that people with disabilities who want to work in the open labour market are supported and enabled to do so' (p. 10). The CES was developed to address historical barriers to employment arising from inadequate education and skills levels, low expectations, societal prejudices and the loss of disability payments. The principles which underpin the strategy assumes that people with a disability are enabled to have jobs to earn a living and make a contribution to society and are supported to maximise their potential by focusing on their capacity as opposed to their incapacity while also receiving the supports that they need to enable them to work (Government of Ireland, 2015, p. 6).

This employment initiative extends across the entire range of people with disabilities and is overseen by a cross- governmental approach in an effort to address the challenges and barriers which have been identified in the Irish context. Central to this has been the model of combining welfare payments and keeping weekly earnings below $€ 120$, which dominated the complexities of the employment landscape for people with disabilities up to 2018. Further concerns arise from the risk of losing access to transport and medical cards, as well as being able to navigate the complex system of supports that might be available to people with disabilities should they wish to work (for a full review see Oireachtas report, 2018). The CES specifically seeks to increase employment rates from $35 \%$ to $38 \%$ by 2024 , a modest increase compared with existing employment rates of $61.4 \%$ of the total population (Central Statistics Office, 2016).

\section{Employee Supports}

Despite the suggested shift to a social model of disability, supports for intending workers still focuses on 'fixing' the individual rather than challenging the social 
structures of work. Employability - a state agency - offers local employment service advice and supports, including job coaches. However, this service is only for those people with a disability who are considered to be 'job ready' (Oireachtas report, 2018).

A Back to Education Initiative (BTEI) facilitates options in further education programmes, and specialist training providers - such as the National Learning Network offer a variety of full- and part-time training programmes. Financial support is available, for some, and the Department of Social Protection allocates the means-tested disability allowance to those of working age (16-66 years) who have injury, disease, a physical or mental disability that has continued or may be expected to continue for at least one year. Applicants are expected to be 'substantially restricted' in undertaking work that would otherwise be suitable for a person of their age, experience and qualifications.

The Health Service Executive (HSE) Training and Occupational Support Service, is provided to people with disabilities aged from $18-65$ years. Until 1 December, 2018 people receiving this benefit could undertake paid work, providing it was of a rehabilitative nature and could earn up to $€ 120$ a week without payments being affected. This has now been extended to $€ 427$ per week without restriction on the nature of work. This policy is somewhat aligned with a change in policy focus to support people with disabilities in their choice of work, enabling them to build individual capacity towards independent living and active citizenship. Recipients are also eligible for a short-term (6-9 months) work experience programme, and a community employment scheme, which offers part-time and temporary job placements within local communities.

\section{Employer Supports}


Additional provisions to support the transition to employment for people with disabilities are aimed at the other partner in the transition process: the potential employer. A wage subsidy scheme provides financial incentive to employers outside the public sector to employ people with disabilities who can work more than 20 hours a week. Funding towards the costs of accommodations such as modifications or special equipment is also available that will allow people with disabilities to take up an offer of employment or to remain in employment. Findings from Scanlon and Kamp (2017) concluded that employers valued increased capacity building on how to support people with disabilities in employment over fiscal supports such as wage subsidies.

The CES seeks to address many of the gaps that have been highlighted within the legislative framework. It can be argued that the philosophy of the CES aligns with some of the principles of the Independent Living Movement in promoting personal choice and autonomy in how people with a disability live their lives. Where governmental initiatives are seeking to support the shift from institutional care to independently chosen community living espoused by the Independent Living Model nonetheless there is a need to listen to the voices of people with disabilities concerning their choices and preferences on issues associated with paid employment. This is of particular importance given that within the Irish context the societal values in relation to social and financial structures favour 'ability' over 'disability' (Bates, Goodley \& Runswick-Cole. 2017). Taken together, this study sought to examine these interrelated issues within the context of transition and employment.

\section{The Current Study}

This research reported in this paper explores the experiences of people with disabilities in Ireland who are planning to make, or have already made, a transition from 
education/training to work. The research conducted was part of a larger study which also sought to understand the attitudes, experience and capacity of employers in regard to the employment and retention of people with disabilities (see Scanlon and Kamp, 2017 for full review). Whilst there is a considerable body of research examining the transitions of young people from school to further education and employment, less is known about people of working age with more complex pathways between education and training, and work. Thus, the primary aim of this research was to identify and explore the structural, contextual, and personal factors that may facilitate or impede the transition experiences of people with disabilities, along the continuum of these transitions.

\section{Method}

\section{Recruitment}

Ethical approval was obtained from the Dublin City University Ethics committee to conduct the research, and an 'ethics as process' approach was adopted throughout the study (Ramcharan and Cutcliffe, 2001). Potential informants were recruited from a range of education and work settings. Information about the study was initially distributed to key gatekeepers (e.g., programme co-ordinators, managers of centres, heads of training centres and access officers in two universities). Where an interest in the research was indicated, the research team went to each centre to meet with individual prospective participants. The team provided detailed information about the project and gave prospective participants an opportunity to ask questions. This exchange afforded the research team the opportunity to explore if prospective participants would require additional support to participate in the project in an effort to promote and facilitate autonomous participation. 


\section{Sample}

Eligible participants were adults of working age (over 18 years), who have a disability, as defined by the World Health Organisation:

Disability is a decrement in functioning at the body, individual or societal level that arises when an individual with a health condition encounters barrier in the environment (WHO 2013).

Thirty-six individuals with a range of disabilites (see Table 1) agreed to be interviewed (one subsequently withdrew from the study). Ages ranged from 21 to 59 years and $46 \%$ $(n=16)$ were female.

\section{TABLE 1 HERE}

In keeping with the "ethics as process approach" every effort was made to ensure that both oral and written information was provided in a format that was fully accessible for each individual participant. The interviewees were assured that their participation was entirely voluntary and there was an on-going opportunity to negotiate consent, take breaks and have a support worker present during the interviews if required. Respondents were also informed that they could withdraw from the interview at any stage and their data would not be used. The respondents reported that they experienced a variety of disabilities and a range of previous work experience as shown in Table 1. All but one of the respondents were Irish nationals.

\section{Data collection and analysis}

A semi-structured interview schedule was developed for this study and was adapted to meet the abilities of the respondents. The interview covered five broad inter-related themes: (1) exploration of past experiences; (2) current preparation; (3) access to employment; (4) support; and (5) progression. The interviews were audio-recorded and 
transcribed verbatim. One interviewee with a hearing impairment provided written answers to an adapted interview schedule. Interviewees were given the opportunity to review the transcripts verify the content and consent to the data being included in the analysis. Confidentiality was preserved: no real names were used in the write-up. The analysis of the data was facilitated by qualitative data software (MAXQDA); content analysis employed a deductive and iterative approach.

\section{Findings}

There was a broad range of experiences, abilities and expectations amongst the respondents, highlighting the challenges that could be expected in supporting transitions to paid employment. For example, there was marked variability in this cohort in terms of the onset of disability, which ranged from birth to mid-adulthood; onset of disability differentially affects the acquisition of education and work skills (Loprest and Magg 2007). Additionally, issues and concerns differ between young people and older people with a disability (Honey, Kariuki, Emerson, and Llewellyn 2014). The varied backgrounds and experiences of the respondents may not reflect the norms imagined for transitions from education to work but, rather, reflect the complex realities for many people with disabilities whose condition may further disrupt any 'career' trajectory in the context of globalised labour markets.

Only a few of the respondents were employed at the time of the interviews, but the majority had some experience of paid employment. Those who had worked full-time at some time in the past had varying patterns of employment history; some had worked consistently in well-paid, skilled jobs but a sudden onset of disability (such as brain injury), or the development of a chronic illness (such as multiple sclerosis), had curtailed their employment. Others had a less stable engagement with work (primarily those who developed a mental illness in early-mid adulthood) and had worked in a 
variety of manual or service occupations, traditionally occupations that have high levels of casual contracts. A change in health status - either an exacerbation of an existing condition or a newly emerging problem - had led to a return to education or training for many respondents; this provided an opportunity to adapt to a change in abilities and/or re-train and consider new employment prospects in the context of changing labour markets. Despite the heterogeneity of the sample, a number of common factors emerged that may facilitate or impede transition processes. These are discussed under the following headings: (1) planning for transition(s); (2) work placements; (3) work readiness; (4) getting and retaining a job.

\section{Planning for transition(s)}

Formal transition planning has commonly been seen as a key response to enable people with disabilities to make a successful move into further education and the workplace (National Disability Authority, 2005; Scanlon and Doyle, 2018). For example, in England, legislation provides a framework for transition planning for students with a learning disability, and importantly, 'a job is identified in transition guidance as a legitimate aim of that transition planning as much as college' (Beyer and Kaehne, 2010, pg. 3). Of the respondents in the current study who are working, only one described any form of transition planning; she was able to identify her career options, and develop a pathway to achieve her goals; she indicated that it would have been beneficial if transition planning had been put in place much earlier:

Have a plan, try and have a plan before you leave [school]. Because I didn't have a plan, I was kind of stuck and it wasn't until I got to [name of course] that I discovered what I really wanted to do. (Brianne, aged 32 with an intellectual disability)

The three graduates who are now working indicated that they had no external transition 
planning; they developed their own plans and strategies that helped them gain employment, (including gaining relevant work experience and higher qualifications)

I did a fair bit of preparation work because I knew that it would be more of a challenge - compared to ordinary people - to land jobs. In every summer in between the years of my degree I worked for companies for little pay...I didn't mind as the work experience, even though not part of my course requirements, enabled my knowledge to stick...I could understand how things worked.(Finn, aged 30, with a hearing impairment)

Similarly, the five respondents who were studying at university acknowledged that a primary degree may not be sufficient to secure work. This reflects, in part, the changing labour market with an increasing emphasis on technological skills and credential inflation, as well as the movement of low-skilled activities away from OECD countries. In addition, at the time of the research all jobseekers were confronted with increased unemployment rates in the wake of the 2008 global financial crisis.

I would have sought career guidance and gone to career talks etc. because I realised that an arts degree especially with, this was early on in the banking crisis and recession, it wasn't going to guarantee you a job ...I realised unless I got a big break further study would have been required (Michael, aged 27 with dyspraxia)

Critically, the ten respondents in vocational training settings did not describe any specific structures or processes to suggest that specific plans were in place for any workplace accommodations if they were successful in gaining employment.

\section{Work placements}

Paid or unpaid work experience during education has been consistently identified as a predictor of future employment for young people with a disability (Landmark, Ju and Zhang, 2010). Several respondents had placements in the workplace as part of their training. These offer benefits to the individual and employer when the placement helps 
to consolidate learning and/or provide an insight into the specifics of a job, any necessary accommodations and/or the particular talents and attributes a person with a disability will contribute to the workplace. The more valued placements for the respondents were those that closely matched their interests and career aspirations. However, two respondents reported being insufficiently challenged during their placements with limited opportunities to learn and integrate in the workplace, a problem in the design of work placement opportunities that is not unique to the work placements of people with disabilities (Shaw and Ogilvie 2010)

Unpaid work has been shown to also have positive benefits on health and wellbeing, particularly for those who are less socially engaged (Piliavin and Siegl 2007).Several respondents described their voluntary work, for example, with the local church. For some, this seemed to be more about establishing a routine and 'having something to do', but was also an important way to not only gain work experience, but also 'transferable' skills or 'key competencies' valued by employers.

\section{Work-Readiness}

For most people in the developed world, and particularly in the context of various 'workfare' regimes, paid work provides financial independence. However, it also contributes to psychosocial wellbeing and, for many, is a source of identity and social status (Harnois and Gabriel 2000 ; Raphael, Bryand, and Rioux 2010). Participation in society in developed economies is commonly measured by how an individual supports themselves and their dependents, and how they contribute to economic growth through paying taxes. The majority of our respondents stressed the importance of having a job, especially for those with a family to support. For some, work was also about maintaining 'good form' and having a routine for the day, 
But I will apply for jobs in the future, yeah, because I need a job and that is helpful for me and I feel when I get the job I feel like in good form... Busy and I have something to do and my time is not boring! (Hassan, aged 44 with schizophrenia)

For others, paid work was associated with a sense of recovery, concepts of 'normality' and being able to contribute to society.
Right and I am willing to contribute to society as long as I get some sort of monetary value in return. It doesn't have to be a lot as long as I can pay my bills, because I want to contribute both financially and morally back to society because I do not want to be a dead weight for society I would rather be a positive than a negative. (Nigel aged 55 with Aspergers, our emphasis)

Eight of those still in training felt they would not be ready to enter the labour market by the end of their current course. This was in large part related to a self-perception that they did not have the skills required for paid work. However, an associated lack of selfconfidence and possible loss of self-esteem and self-efficacy was articulated, a situation that this is not uncommon for those with a history of mental illness (Corrigan, Larson and Rüsch 2009).
well as far as jobs are concerned what I hope to do is... the original plan was maybe to go on and do level 6 and go on to further education but I don't think I'm strong enough to do it at the moment... then after five years I can go and apply. (Keith, aged 47 with dual diagnosis)

Six of the respondents described how they had left jobs because of some deterioration in their mental health, potentially contributing to an increased anticipation of future discrimination in the workplace. This finding supports research commissioned by Amnesty International suggesting that over two-thirds of respondents had decided to stop working because of how they thought others might react to their mental health problem (MacGabhann et al. 2010). The research by Amnesty International, and the 
current research, underscore the particular complexities encountered by those with mental health problems in terms of real, and perceived, stigma.

Four of our respondents described themselves as determined, stubborn, 'fiercely independent', with a desire for control in their lives. These respondents were more likely to be in paid employment, or to have gained some experience of work since leaving training/education. Self-determination, defined as a set of 'skills, knowledge and beliefs that enable a person to engage in goal-directed, self-regulated, autonomous behaviour' (Shogren 2013 p5), has been identified as an important characteristic of successful transition (Wehmeyer, Gragoudas and Shogren, 2006). This set of skills and commitments aligns with the ethos of the Independent Living Movement, and has implications for the focus of transition planning. The enhancement of perceptions and skills associated with self-determination may be particularly important for people who have lost confidence in their own abilities, (Bevan et al. 2013) and for those with an intellectual disability. At the same time, for some of our respondents, there was a perception that the skills learnt on vocational courses did not always align with skills sought by employers. Interestingly within the employer component of this research only a minority of respondents indicated that skills they sought were lacking ( See Scanlon and Kamp, 2015 for full overview ).

The extent to which this is the case is beyond the scope of this research, but the perception it is likely to have a negative consequence on self-perceptions of workreadiness.

\section{Getting and retaining work}

The respondents were generally realistic as to their prospects of getting a job; they were well aware of the additional challenges in securing paid employment during a period of economic recession. Employment assistance provided at training centres appeared to 
replicate those provided to the non-disabled community, consisting primarily of $\mathrm{CV}$ preparation, mock interviews and help with searching databases for vacancies. As with others seeking work in a labour market with limited opportunities, the respondents expressed frustration when sending out multiple CVs without receiving any acknowledgement of applications.

I applied a few weeks ago... and not a word back on any of them and that was about three or four weeks ago and no phone call or nothing back (Nathan, aged 45, with schizophrenia)

One respondent had a successful six-month internship with a well-known multi-national after her degree, and, while she felt this had helped her get called for interview, it had not led to full-time work:

I find I still get interviews, but then nothing comes of it. So I don't know are they just interviewing me for the sake of it, for the statistics or the like (Saoirse, aged 29 with visual impairment)

Whilst non-disabled job-seekers experience a similar lack of responses and setbacks, the literature suggests this can have particularly negative effects on self-esteem and perceptions - real or otherwise - of discrimination (Corrigan et al. 2009). A few respondents had been successful in finding short-term work and while this had enabled them to build experience, they demonstrated some individualization of risk and were concerned as to how this may be perceived by future employers.

so I had about 10 short-term positions but I haven't had any full time positions, which is killing me - I have got good organisations on my CV but again it looks like I am jumping ship all the time (James, aged 38 with muscular dystrophy)

For some respondents, there was a perception that a prospective employer may view gaps in CV negatively, reducing the likelihood of being called for interview. Deciding 
if, or when, to disclose a disability to potential employers represented a major concern for most of the participants.

You're not even, they're not going to look at your CV when they see you've got a medical problem or when they see you've been to [name of training college], you know what I mean, or if you mention special education or special needs or anything (Ultan, aged 59, bipolar)

Perceptions and experience regarding disclosure were consistently negative, regardless of the age of the respondent. Yet, disclosing a disability allows for the identification of accommodations that might be needed to fulfil the requirements of a job during the hiring process or early on in the job (Granger 2000, cited by McDowell and Fossey 2015; Scanlon and Kamp, 2017). Some of our respondents required specific equipment to be able to work effectively (e.g., text to speech software, induction loops), whereas others required more general accommodations such as modifications or extensions to training schedules and additional supervision. Employers can be more familiar with meeting the needs for people with physical disability, rather than other types of disability, and research indicates that their knowledge of the range of possible workplace supports can be limited (McAlpine and Warner 2002; Unger and Kregel 2003). Whilst reasonable accommodations are clearly important in achieving a successful transition, and the costs of accommodations are often no greater than the costs of accommodations provided to non-disabled employees (Schur et al. 2014), our respondents suggest that there can be some delay, and even reluctance, in ensuring that specific needs are met in a timely fashion, even with full disclosure.

This is kind of a quick fix, [and I thought that] maybe something better will come, and then they got me a stand in so it got a little better, but it was always like 'is that enough' 'will that do?' (Stephen, aged 25, visual impairment) 
Related to workplace accommodation is the need for flexible scheduling of work time or reduced hours, an accommodation that can be valued by diverse groups of employees, including parents. Several respondents indicated that they would prefer parttime work, as this was viewed as a way to manage fatigue and stress-related conditions. Twelve of the respondents still in training and education, or not working, indicated that they would need to consider a different type of job in the future because of the change in their health status.

but you see the thing is with me - I get tired sometimes and especially after lunch. So I don't know how I would perform in a job because I get so tired. But then again maybe I would get used to it (Barbara, in her 30's, with acquired brain injury)

Greater flexibility at work for example, reduced hours or working from home, would not only benefit people with a disability but can make the workplace more family friendly for all employees. However, this strategy is not without risk for employees, including employees with disabilities, as working part-time can hinder on-the-job training opportunities and career progression given the norm of the full-time job prevails at the local level, despite changes in the nature of work in the $21^{\text {st }}$ Century

A small number of respondents expressed the desire to be self-employed and it is likely that this is related to the need for modified work practices to accommodate the fluctuating nature of some of the types of disability. Research indicates that rates of self-employment are higher for people with disabilities and that self-employment can result in higher levels of job satisfaction (Pagan 2009). In addition, having some control over working hours can be helpful in preventing loss of productivity, with resultant risks to financial resources, or the exacerbation of symptoms. Opportunities for selfemployment depend on access to capital - both economic and social - but also on a 
range of other supports; for Pagan, this is an area that is something of a missed opportunity in the policy context. In contrast, employers' limited awareness about the impact of disability can hinder workplace adjustments, for example, one respondent described how a lack of knowledge about her condition affected an employer's behaviours:

I've worked in other places where I wasn't allowed up or down stairs, people weren't sure whether I should be sitting in front of a computer (Nessa, in her 30's, with epilepsy)

In contrast, a second employer asked her to speak about her condition at a staff meeting, give a demonstration about what to do in the event of her experiencing a seizure, and to share information on who to contact; this openness reduced any concerns and her disability was mediated as an issue in the context of her work. Attitudes of supervisors and co-workers can affect the socialisation of new employees, and particularly those who may have a disability that is not immediately visible, thereby increasing the likelihood that they will become fully accepted members of the workforce (Schur, Kruse and Blanch , 2005). Of course, this full acceptance is not always the case as reported by one respondent with an intellectual disability. She had enjoyed working in a small family business, however, when that business closed, she worked briefly in several large organisations but felt that:

Yeah, the other people weren't, hadn't got time for me, they didn't want anybody who were slow. I noticed that they'd give all the jobs to people who are not slow (Marie, in her 40's, intellectual disability)

This commentary shows the lack of engagement with the notion of what a person can do, rather than what they cannot do. Marie now considers herself to be retired, as she does not want to risk being exposed to any perceived discrimination again. 
Finally, fear of losing social security benefits may inhibit some respondents from seeking paid work, or moving from part-time to full-time employment. In the context of welfare reforms in the wake of the financial crisis and recession in Ireland, individuals could effectively be financially penalised in moving off benefits into a low paid job with few opportunities for advancement (Barnes and Mercer 2005), particularly in a context where many able-bodied and experienced workers were competing for limited employment opportunities. While none of the respondents described personal experience associated with a re-allocation of benefits, there was a belief by many that re-allocation would not be an easy process if a job did not work out. A system that supports a prompt re-allocation of benefits may counter this belief amongst people with disabilities. However, there is no evidence to suggest that reforming benefit policies effectively improves employment rates amongst those with a disability (MacInnes et al. 2014). Indeed, the strongest predictor of employment levels of persons with a disability is the employment rates of the general population (OECD 2003, cited by NDA 2009).

\section{Conclusion}

The majority of the respondents in the study reported here want to work, but identified persistant barriers in moving into and retaining paid employment, including both perceived and actual limits to their work-readiness, concerns related to the benefits and risks of disclosure, efficient provision of accommodations and the need for greater flexibility in the conditions of employment. Whilst there was a clear expectation that they could work, there was an acknowledgement that this represented a considerable personal challenge, particularly as Ireland continued the process of economic recovery and brought down rates of unemployment.

Research on transition to work planning has mainly focussed on young people leaving school for the first time. This research focused on people aged 18 and over 
where there is less evidence of what constitutes best practice for a social group who may be making the transition into paid employment for the second or even third time, and who have significant life experience to hand. International evidence suggests that such planning is most effective when, amongst other things, it is person-centred, includes active involvement and real work experience, is supported by interagency collaboration (Powers et al. 2005), and facilitated by staff skilled in finding and matching available work to people (Beyer and Kaehne 2010). Such person-centred planning resounds with the philosophy of the Independent Living Movement and the commitment it implies for people with disabilities have the right to choose the supports they require. While this suggests individualised funding of supports and recognition of people with disabilities as being the experts on their needs, this should not be at the cost of individualizing the issue of disability support. A social model of disability implies that society with its able-ist norms and the acceptance of precarious work, must be called to account.

Encouragingly, the recently published Comprehensive Employment Strategy for People with Disabilities recognises "the need to promote job retention and re-entry to work for those individuals who acquire a disability during their working years" (Government of Ireland, 2015, p.19). The suggested developments include a programme to train 'disability champions' to support colleagues returning to work. This is a potentially useful strategy in, for example, supporting safe and sustainable return to work for those who acquire a disability through injury at work (Shaw et al. 2008). Disability champions could respond to the needs identified in this research to ensure that all stakeholders in the transition process - the prospective worker, the employer and the educator - work together to develop realistic, meaningful training courses and work 
placements that are matched to employer, and worker, needs in the immediate, and longer, term future.

The lack of formal transition plans identified in this research might be explained by the majority of these respondents expecting to stay in education/training for the foreseeable future, despite being encouraged by their tutors to apply for jobs. But, in the context of changing work patterns, people with disabilities also need alternatives to securing work with an employer. In some cases, this may include entrepreneurial skills for those who intend to become self-employed. Policy makers could do more to encourage self-employment amongst people with a disability by specifically focussing on their needs through providing seed-capital and ensuring continuity of benefits (Pagán 2009).

The disabilities of most of our respondents were not overt, and many expressed their reluctance to disclose their disability to prospective employers. The provision of effective workplace accommodation relies on the person disclosing their needs, yet, until discrimination, real and perceived, is tackled and reduced, it seems likely that the reluctance to disclose a disability will persist. There is also a need for accessible information for workers, employers, rehabilitation professionals and other specialists regarding how to best select and implement reasonable accommodation that is tailored to meet the needs of the individual and their workplaces (McDowell and Fossey, 2015) ${ }^{1}$. This need will be met, in part, by the Government of Ireland funding the establishment of an employer helpline to provide guidance and peer support in relation to the employment of people with disabilities (Government of Ireland, 2015, p22). 
The high levels of unemployment amongst people with a disability is both a social and economic concern across many jurisdictions. Unemployment can act as a major barrier in achieving greater social inclusion (Waddell and Burton, 2006). Furthermore, in a context where paid work is valorised as the mechanism to material security, poverty and dependence can be common experiences for people with a disability (Barron and Ncube, 2010). Yet, in a recovering economy, people with disabilities can help to fill the expected labour forces shortages associated with demographic change and population ageing (Shur et al., 2014), as well as bringing their unique perspectives and skills to increasingly diverse workplaces. The respondents included in this study are willing and able to contribute in the workplace, but for some, there remain persistent barriers - both real and perceived - that if addressed, could facilitate the seamless transition for people with disabilities, not only from education and training to employment, but also to higher levels of social and cultural inclusion.

\section{References}

Barnes, C. and Mercer, G. 2005. "Disability, work, and welfare: challenging the social inclusion of disabled people". Work, Employment and Society, 19 (3): 527-545.

Barron, T. and Ncube, JM. eds. 2011. Poverty and Disability. The Disability and Inclusive Development Series. London: Leonard Cheshire Disability.

Bates, K., Goodley, D., and Runswick-Cole, K. 2017. Precarious lives and resistant possibilities: the labour of people with learning disabilities in times of austerity. Disability and Society, 32:2, 160-175.

Bevan, S., Zheltoukhova, K., Summers, K. Bajorek, Z., O’Dea, Li \& Gulliford, J. 2013. Life and employment conditions of young people with chronic conditions. Lancaster: The Work Foundation. 
Beyer, S. and Kaehne, A. 2010.Transition to employment: the role of Getting a Life in developing an employment pathway for people with learning disabilities. Cardiff: Welsh Centre for Learning Disabilities.

Central Statistics Office. 2016.This is Ireland: highlights from Census 2016. Dublin: Stationary Office.

Clayton, S., Barr, B., Nylen, L., Burström, B., Thielen, K., Diderichsen, F., Dahl, E. and Whitehead, M. 2011. Effectiveness of return-to-work interventions for disabled people: a systematic review of government initiatives focused on changing the behaviour of employers. European Journal of Public Health, 22 (3): 434-439.

Corrigan, P.W.,Larson, J.E. and Rüsch, N. 2009. "Self-stigma and the 'why try' effect: impact on life goals and evidence-based practices." World Psychiatry, 8(2): 758.

DeJong, G. (1979). Independent Living: From social movement to analytic paradigm. Archives of Physical Medicine and Rehabilitation, 60, 435- 446.

Department of Justice, Equality and Law Reform. 2006. Guide to the Disability Act 2005. Dublin: Stationary Office.

Fleming, P., McGilloway, S., and Barry, S. (2016). The successes and challenges of implementing individualised funding and supports for disabled people: an Irish perspective. Disability and Society, 21; 10, 1369-1384.

Government of Ireland. 2015. Comprehensive Employment Strategy for People with Disabilities: 2015-2024. Dublin: Government of Ireland.

Government of Ireland. 2018. Review of supports available to people with disabilites transitioning from education or training into employment. Dublin. House of the Oireachtas.

Harnois G and Gabriel G. 2000. Mental health and work: impact, issues and good practices. Geneva, World Health Organization.

Honey, A., Kariuki, M., Emerson, E., and Llewellyn, G. 2014. "Employment status transitions among young adults, with and without disability. "Australian Journal of Social Issues, 49(2):151-170.

The Irish Examiner (2015) https://www.irishexaminer.com/ireland/state-agencies$\underline{\text { missing-disability-targets-307852.html }}$ 
Johnson, DR., Stodden, RA., Emanuel, EJ.,Luecking, R. and Mack, M. 2002. “Current challenges facing secondary education and transition services. What research tells us.” Exceptional Children, 68: 519-531.

Landmark, LJ.,Ju, S. \& Zhang, D. 2010. "Substantiated best practices in transition: Fifteen plus years later." Career Development for Exceptional Individuals, 33 : 3:165-176.

Lafargue. P. 1883. The Right To be Lazy and other studies. Charles H. Kerry and Company Co-operative. Chicago. USA.

Lewis, M. 2011. "When Irish Eyes Are Crying." In Vanity Fair. United States: Conde Naste.

Loprest, P. and Maag, E. 2007.“The relationship between early disability onset and education and employment." Journal of Vocational Rehabilitation, 26 (1): 4962.

MacGabhann, L., Lakeman, R. McGowan, P., Parkinson, M., Redmond, M., Sibitz, I. et al. 2010. Hear my voice: The experience of discrimination by people with mental health problems. Dublin: Amnesty International.

MacInnes, T., Tinson, A., Gaffney, D., Horgan, G. and Baumberg, B. 2014. Disability, long term conditions and poverty. London: New Policy Institute, for the Joseph Rowntree Foundation.

McAlpine, DD. and Warner, L. 2002. Barriers to employment amongst persons with mental illness: a review of the literature. New Brunswick: Rutgers University.

McDowell, C. and Fossey, E. 2015 "Workplace accommodations for people with mental illness: A scoping review." Journal of Occupational Rehabilitation, 25: 197-206.

Millbank Foundation for Vocational Rehabilitation. (2003). A study of employer attitudes toward hiring individuals with disabilities. Florida: Centre for Information, Training and Evaluation Services.

National Disability Authority. 2009. Employment Policy and Practice for People with Disabilities in Three International Jurisdictions. Dublin: NDA.

National Disability Authority. 2005. Guidelines for purchasers of disability equality training. Dublin. NDA. 
Needels. K. \& Schmitz.P. (2006) Economics and social costs and benefits to employers of retraining recruiting and employing disabled people and/ or people with health conditions: A Review of the evidence. Department for Work and Pensions. Norwich.

Organisation for Economic Co-operation and Development. 2010. Sickness, Disability and Work: Breaking the Barriers. Paris: OECD.

Oliver. M. (2013). The social model of disability: thirty years on. Disability and Society, 28 (7): 1024 -1026.

O’Toole, J. 2014. Review of different approaches to work skills development for disabled young people (14-25) and disabled working adults in the UK and internationally. London: Institute for Policy Studies in Education (IPSE).

Pagán, R. 2009.“Self-employment among people with disabilities: evidence for Europe." Disability and Society, 24 (2): 217-229.

Piggott, LA. and Houghton, A. 2007. "Disability and transitions from education to work." International Journal of Lifelong Education, 26(5): 573-587.

Pilivin, JA and Siegl, E. 2007. "Health benefits of volunteering in the Wisconsin Longitudinal Study. "Journal of Health and Social Behaviour, 48(4): 450-464.

Powers, KM., Gil-Kashiwabara, E., Geenan, SJ.,Powers, LE., Balandran, J. and Palmer, C. 2005. "Mandates and effective transition planning practices reflected in IEPs.” Career Development for Exceptional Individuals, 28(1): 47-59.

Ramcharan, P. and Cutcliffe, J. R. 2001. "Judging the ethics of qualitative research: considering the ethics as process model." Health and Social Care in the Community, 9: 358-366.

Raphael, D. Bryant, T. and Riou, M.H. 2010. Critical Perspectives on Health Illness and Health Care. Canadian Scholars Press.

Rinehart, J. 2006. The Tyranny of Work: Alienation and the Labour Process. Toronto: Thomson Nelson.

Sayce, L. 2011. Getting in, staying in and getting on. Disability employment support fit for the future. Independent Review for the Department of Work and Pensions. London: The Stationary Office. 
Scanlon, G. and Kamp, A. 2017. Transitions from education and employment for people with disabilites. Dublin. The National Disability Authority.

Scanlon, G. and Doyle. A. (2018). Progressing Accessible Supported Transitions to Employment. Dublin. Dublin City University

Shaw, S. and Ogilvie, C. 2010. 'Making a virtue out of a necessity: Part time work as a site for undergraduate work-based learning,' Journal of Industrial Training, $34,(89), 805-21$.

Shaw, W., Hong, Q-n., Pransky, G. and Loisel, P. 2008 “A literature review describing the role of return-to-work coordinators in trial programs and interventions designed to prevent workplace disability. Journal of Occupational Rehabilitation, 18 (2): 2 -15.

Shier, M., Graham, J.R. and Jones, M.E. 2009. "Barriers to employment as experienced by disabled people: a qualitative analysis in Calgary and Regina, Canada." Disability and Society, 24(1): 63-75.

Schur, L., Nishii, L., Adya, M. Kruse, D., Bruyère, S.M. and Blanck, P. 2014. "Accommodating employees with and without disabilities." Human Resource Management, 53 (4): 593-621.

Schur, L., Kruse, D. \& Blanck, P. 2005. 'Corporate Culture and the Employment of Persons with Disabilities', Behavioural Sciences and the Law, 23, pp. 3-20.

Shogren, K.A. 2013. Self-determination and transition planning. Baltimore: Paul H. Brookes Pub Co.

Standing, G. 2011. The Precariat: The new dangerous class. London: Bloomsbury Academic.

United Nations. (2006). The Convention of the Rights of People with Disabilities. United Nations. Geneva.

Unger, D. (2002) 'Employer's attitudes toward persons with disabilities in the workforce: myths or realities?' Focus on Autism and Other Developmental Disabilities, 17(1), pp. 2-10.

Waddell, G. and Burton, AK. 2006.Is work good for your health and well-being? UK: The Stationary Office. 
Watson, D. and Nolan, B. 2011. A social portrait of people with disabilities in Ireland. Dublin: Department of Social Protection and The Economic and Social Research Institute.

Watson, D., Banks, J. and Lyons, S. 2015. Educational and employment experiences of people with a disability in Ireland: an analysis of the National Disability Survey. Research series number 42. Dublin: The Economic and Social Research Institute.

Waterhouse, P., Kimberley, H., Jonas, P., Glover, J. (2010) What would it take? Employer perspectives on employing people with a disability. Canberra: National Centre for Vocational Educational Research.

Wehmeyer, M. L.,Gragoudas, S., and Shogren, K.A. 2006. “Self-determination, student involvement, and leadership development." In P. Wehman (Ed.) Life beyond the classroom: transition strategies for young people with disabilities $\left(4^{\text {th }} \mathrm{ed}\right)$, edited by P. Wehman. 4-69. Baltimore: Paul H. Brookes.

World Health Organization. (2013). World disability report. Geneva: WHO

White, G., W, Simpson, J., L, Gonda, C., Ravesloot, C., and Coble. A. (2010). Moving from independence to independence: A conceptual model for better understanding community participation of centers for independent living consumers. Journal of Disability Policy Studies, 20 (4): 233-240. 